\title{
Ameloblastic fibro-odontoma: case report
}

\author{
Fibro-odontoma ameloblástico: relato de caso
}

\author{
Cintia Gollo PIVA ${ }^{1}$ \\ Daniela Cristina MIYAGAKI ${ }^{1}$ \\ Maria Salete LINDEN ${ }^{1}$ \\ Ferdinando DE CONTO' \\ Isadora RINALDI' \\ João Paulo DE CARLI
}

\section{ABSTRACT}

The ameloblastic fibro-odontoma is a benign, mixed, asymptomatic and rare odontogenic tumor that can easily be confused radiographically and histologically with other diseases. Usually it affects a population between the first and second decades of life, is more frequent in the mandible and shows predilection for males. This lesion, characterized by dental agenesis at the tumor site, has no predilection for anatomical region; however, an increase of intraoral volume may cause mild facial asymmetry. It shows slow but expansive growth, and is a well-defined radiolucent lesion, usually unilocular, with radiopacity inside. Normally surgical removal is conservative and the prognosis is favorable. This article reports a case of ameloblastic fibro-odontoma treated by surgical removal and follow-up of two years. The aim of this work was to study the ameloblastic fibro-odontoma in its entirety, seeking to inform clinicians about the best diagnostic and treatment methods for this type lesion.

Termos de indexação: Diagnosis. Odontoma. Therapeutics.

\section{RESUMO}

O fibro-odontoma ameloblástico é um tumor odontogênico misto benigno, assintomático e raro, que pode ser facilmente confundido radiograficamente e histopatologicamente com outras enfermidades. Normalmente atinge uma população entre a primeira e a segunda décadas de vida, sendo mais frequente em mandíbula e com predileção pelo sexo masculino. Este tumor caracteriza-se pela agenesia dentária no local do tumor, sem predileção por região anatômica, e por um aumento de volume intrabucal, podendo causar leve assimetria facial. Apresenta crescimento lento, porém expansivo; revela-se como uma lesão radiolúcida bem definida, normalmente unilocular, com radiopacidades no seu interior. Normalmente a remoção cirúrgica é conservadora e o prognóstico é favorável. O presente trabalho relata um caso clínico de fibro-odontoma ameloblástico tratado por meio de remoção cirúrgica e com acompanhamento de dois anos. O objetivo deste trabalho foi estudar o fibro-odontoma ameloblástico em sua integralidade, buscando expor ao cirurgião-dentista os melhores métodos de diagnóstico e tratamento para tal lesão.

Termos de indexação: Diagnóstico. Odontoma. Terapêutica

\section{INTRODUCTION}

The ameloblastic fibro-odontoma (AFO) is an uncommon, mixed odontogenic tumor that represents from 1 to $3 \%$ of all the odontogenic tumors ${ }^{1-5}$ and could be confused with various lesions. It is of significant importance due to its potential for growth. This benign tumor has been defined by the World Health Organization (WHO) as a neoplasm composed of odontogenic epithelial proliferation on a stroma of ectomesenchymal cellular tissue that presents variable degrees of inductive interchanges with the formation of dentin and enamel matrix.

AOF affects a young population with a mean age of 19 years. They are more frequent in the posterior region of the mandible, followed by the posterior region of the maxilla $a^{4,6-7}$.

Buchner et al. ${ }^{7}$, in their research showed that AFO has a discrete predilection for the male gender ${ }^{4,8}$, however, some studies, and the WHO affirm that there is no predilection for gender and localization ${ }^{5,9-10}$.

Lesion growth is slow, but expansive, and may cause an increase in volume within the mouth, and also

\footnotetext{
${ }^{1}$ Universidade de Passo Fundo, Faculdade de Odontologia. Campus Universitário, São José, 99052-900, Passo Fundo, RS, Brasil. Correspondência para / Correspondence to: JP DE CARLI. E-mail: <joaodecarli@upf.br>.
} 
cause slight asymmetry in the patient's face ${ }^{7,11}$. Even with the intraoral increase in volume, the color of the mucosa is not changed, but its consistency becomes hardened. The lesion is normally asymptomatic, ad is not associated with

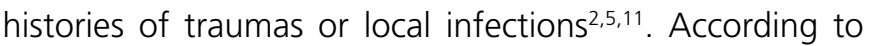
De Riu et al. ${ }^{11}$ and de Souza Tolentino et al. ${ }^{12}$, The tumor may inhibit eruption of the tooth involved, or displace it without affecting its vitality, and the tooth may be found in the midst of the tumor mass.

Because AFO is asymptomatic, it is normally only diagnosed when the patient has a routine panoramic radiograph taken, or when the parents perceive that eruption of some tooth is delayed ${ }^{3-4}$. Cavalcante et al. ${ }^{13}$ related that the increase in volume is also a reason for the children's families to seek dentists, although the studies of Boxberger et al. ${ }^{4}$ showed that only a small portion of the cases presented expansion.

Radiographically, the AFO presents as a wellcircumscribed unilocular or multilocular radiolucent lesion that may contain a mass in it, with radiopaque foci or variable radiodensity compatible with the material of the dental structure ${ }^{14-15}$. Buchner et al. ${ }^{7}$ conducted a study in which they revealed that approximately $90 \%$ of the lesions were unilocular and that multilocular lesions were uncommon, however, present in $10 \%$ of the cases.

In histopathological exams, odontogenic tumors tend to reproduce their tissue of origin; that is, they may resemble the enamel or dental pulp organ, as well as contain immature mineralized tissue fragments, such as enamel, dentin and cement ${ }^{15-16}$.

As differential diagnosis of this lesion, according to the WHO and Buchner et al. ${ }^{7}$ we may consider the odontoma and ameloblastic fibroma.

As the AFO lesion is encapsulated, non-invasive and easily becomes detached, in the majority of cases, the treatment is conservative surgery that may be an excision or nucleation by curettage $\mathrm{e}^{3-4,7,10-11}$.

Buchner et al. ${ }^{7}$ showed that recurrence of AFO is uncommon and normally occurs due to a residual lesion resulting from inadequate surgical removal at the time of initial treatment. The prognosis is favorable, bearing in mind that transformation into the ameloblastic fibrosarcoma is rare ${ }^{15}$.

In dental practice, since dentists are subject to coming across lesions that lead to suggesting various differential diagnoses, as their clinical, histopathological or radiographic aspects are similar, the aim of this article was to report a clinical case of AFO treated by surgical removal, with clinical radiographic follow-up for a period of two years. A logical sequence of diagnosis, treatment and clinical follow-up of the AFO was established, with the aim of studying the ameloblastic fibro-odontoma in its entirety, to inform dentists about the best methods of intervention in this pathology.

\section{CASE REPORT}

The patient, a 19-year-old Caucasian woman, sought dental care in April 2012 for third molar extractions. In the intra and extraoral exams no increase in volume of change in gingival color were verified. The patient denied any changes in health, and presented to local discomfort.

In the panoramic radiograph (Figure 1) agenesis of tooth 38 was identified. A closer observation revealed a well-defined radiolucent image of about $25 \mathrm{~mm}$ in diameter, localized in the distal portion of tooth 37, without present a direct relationship with this tooth. Within this image, discrete radiopaque foci were noted. During anamnesis, the patient informed that she had had tooth 48 extracted three months previously, and that she had been using an orthodontic appliance for the last three years.

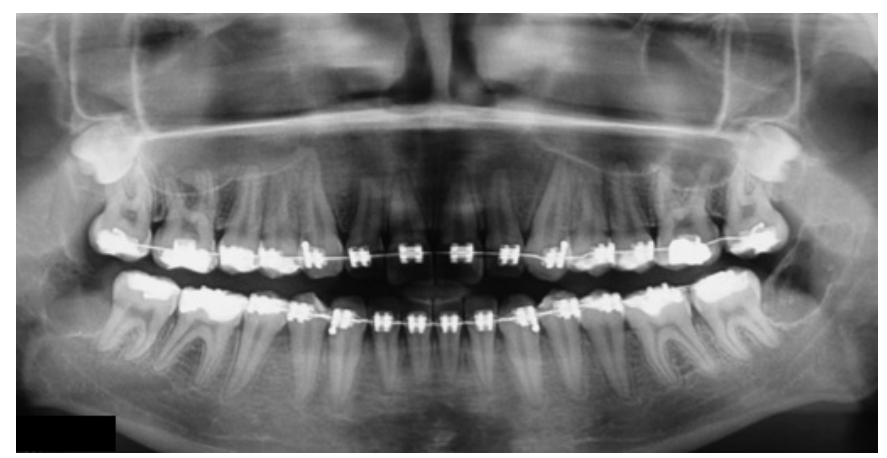

Figure 1. Panoramic radiograph showing a radiolucent image with discrete radiopaque point inside it and well defined margins in the region of the ascending ramus of the mandible on the left.

In May 2012, with a presumed diagnosis of AFO, calcifying odontogenic and calcifying epithelial odontogenic tumor, an incisional biopsy of the lesion was performed, and seven fragments of soft tissue were removed, of which two were white and the remainder brown, all grossly spherical and friable, together measuring $4 \times 3 \times 1 \mathrm{~mm}$.

In the histopathological exam results, the cut stained by the HE technique showed an odontogenic epithelium sometimes in cords, and sometimes in islands (Figure 1), with juxtaposed ameloblasts that resembled the 
tooth germ, superimposed on loose connective tissue with starred fibroblasts. Also observed, was the presence of mineralized tissue similar to cement and areas resembling enamel. With these characteristics, the initial definitive diagnosis was ameloblastic fibro-odontoma (AFO).

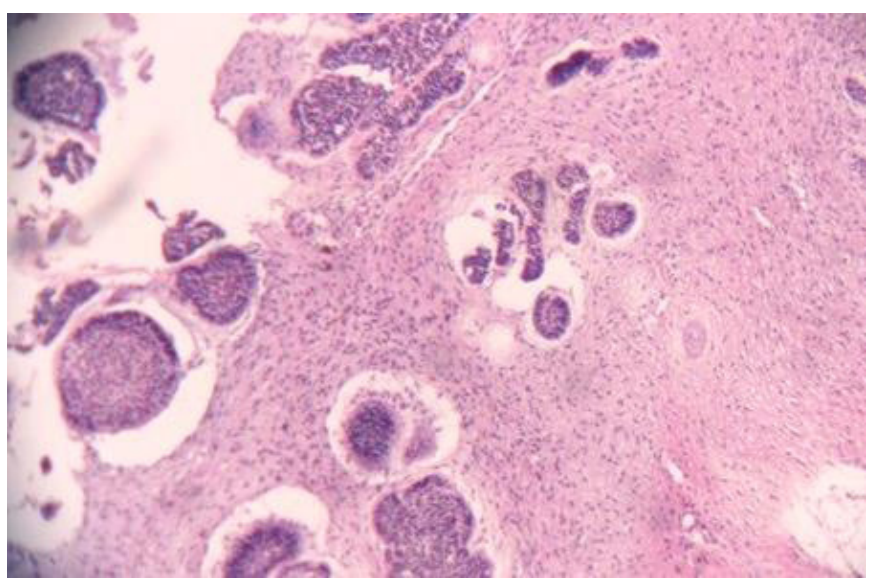

Figure 2. Photomicrograph revealing epithelial islands and cords in mesenchymal stroma similar to that of dental papilla. HE Staining, $100 \times$ magnifications.

Conservative surgical treatment (Figure 3) was performed under general anesthesia, follow by meticulous curettage at the tumor site. The surgical part removed was composed of a fragment of elongated, light soft tissue with a papillary, elastic surface, containing a capsule around it, measuring $19 \times 7 \times 5 \mathrm{~mm}$ (Figure 4). This was sent for histopathological exam, to obtain confirmation of the initial diagnosis.

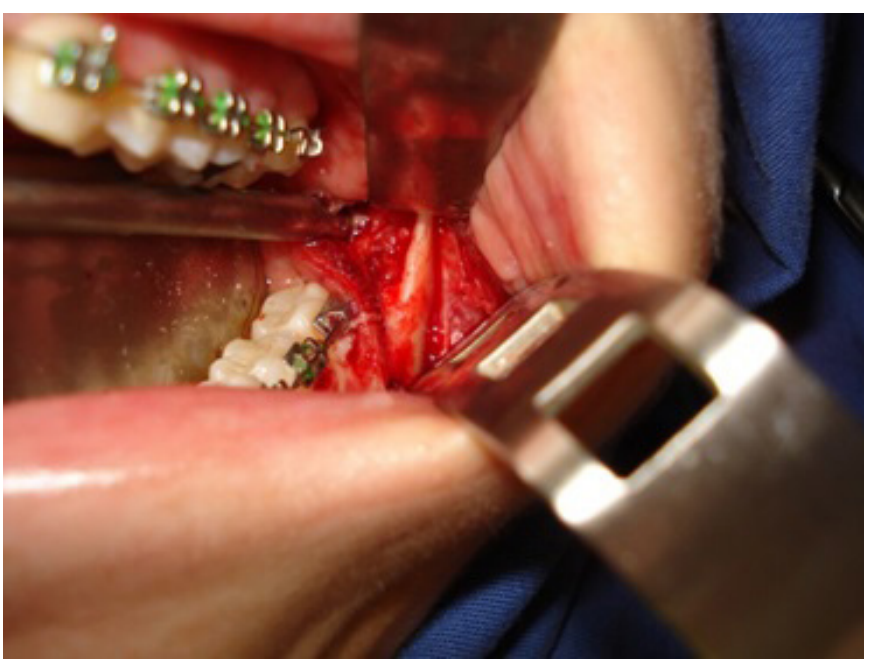

Figure 3. Conservative surgery and curettage for removal of the odontogenic tumor.

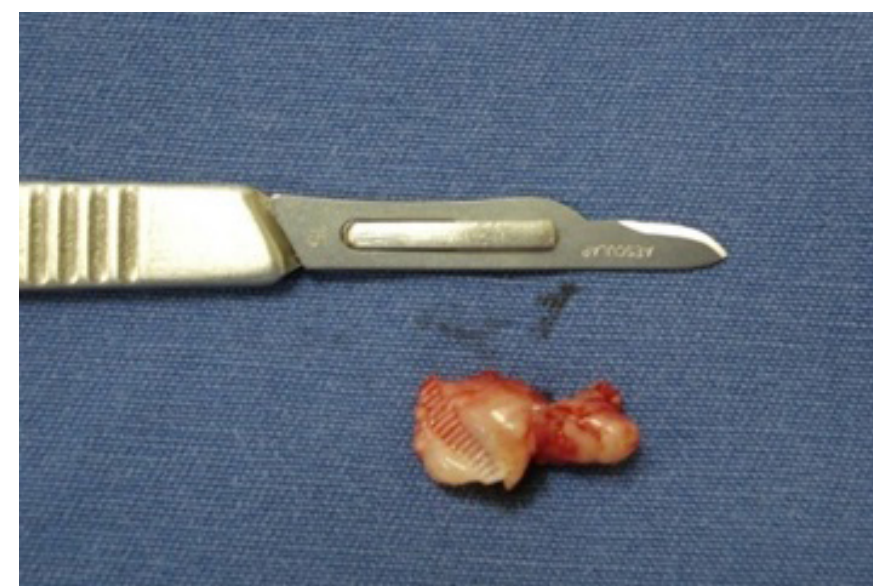

Figure 4. Surgical part removed in the second biopsy

The cuts examined (Figure 5) confirmed the diagnosis of AFO, sowing an odontogenic epithelium in ample cellular proliferation, forming numerous islands with shoots or cellular cords proliferating on the loose connective tissue that resembled dental pulp. Also observed, were mineralized tissues similar to dental cement and spongy, hemosiderin, trabecular bone fragments.

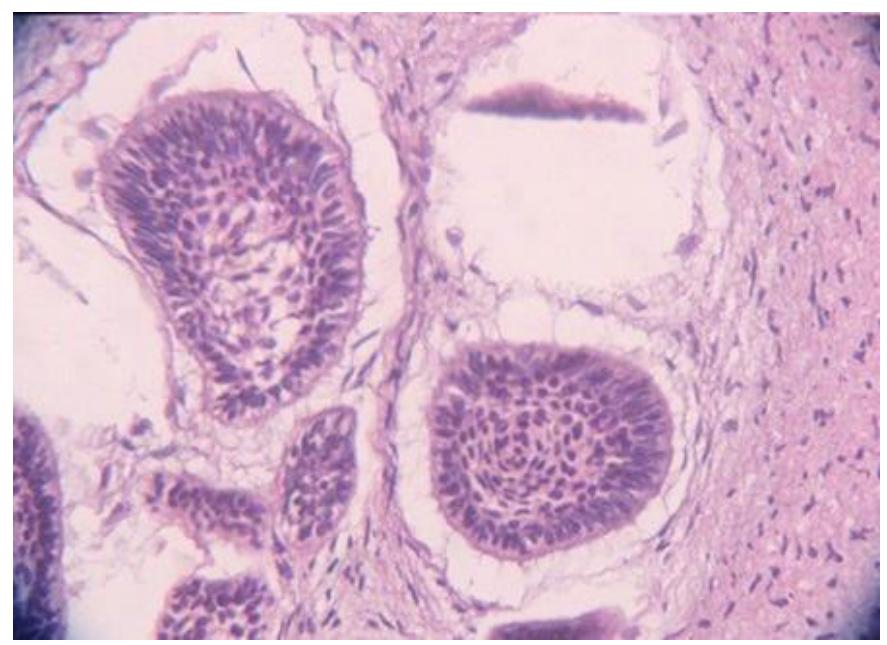

Figure 5. Photomicrograph exhibiting epithelial island containing cylindrical cells at the periphery and cubic cells in the central area, surrounded by a white halo, suggesting area occupied by enamel. HE Staining, 400x magnification.

In the post-operative control at 30 days, the patient returned without change in sensitivity or sign of lesion of the inferior alveolar nerve. The case presented continues to be followed-up, and the radiograph taken in July 2014 showed a radiopaque image at the site of the lesion, suggesting complete bone remodeling, confirming that the treatment performed was successful and the disease completely cured (Figure 6). 


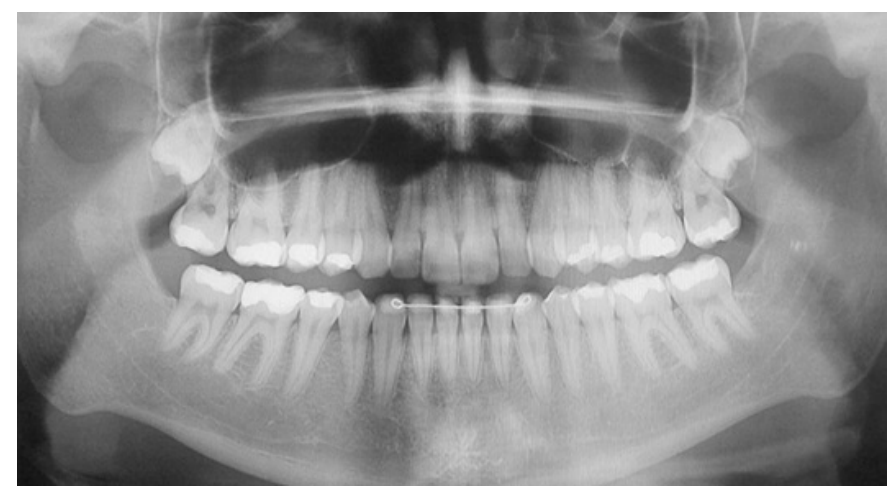

Figure 6. Follow-up panoramic radiograph (25 months) showing complete bone remodeling.

\section{DISCUSSION}

The ameloblastic fibro-odontoma is a rare disease that affects a young population, with a mean age of 21 years, according to Buchner et al. ${ }^{7}$, and the area most affected is the posterior mandibular region. In the present study, the case related is compatible with the mean age, since the patient was 19 years old when the AFO was discovered in the posterior mandibular region on the left.

The tumor diagnosis was confirmed by association of the panoramic radiograph, which showed a well circumscribed radiolucent image with varying radiodensity within it, with the intraoral exam and biopsy performed. There are other exams that may help with differential diagnosis, such as computed tomography. The treatment for AFO is conservative surgery with curettage, since the lesion is presented encapsulated and is non-invasive. Thus, its prognosis is favorable and the rate of recurrence is low. In the case of the tumor described, the differential diagnosis included lesions with mixed radiographic patterns, such as: Calcifying Odontogenic Epithelial Tumor (COET), Calcifying Odontogenic Cyst (COC), Complex Orthodontia and Adenomatoid Odontogenic Tumor (AOT) ${ }^{15}$.

Boxberger et al. ${ }^{4}$, Buchner et al. ${ }^{7}$ and Zouhary et al. ${ }^{8}$ affirmed that this tumor presented predilection for the male sex, however, the World Health Organization and authors such as Nelson \& Thompson ${ }^{5}$, Hunter et al. ${ }^{9}$ and Lúcio et al. ${ }^{10}$ affirmed that there was no predilection for gender or localization.

The patient in this case was Caucasian, however, on analyzing the literature of the area, no information was found about the prevalence of AOF in different ethnic groups.

The study of Buchner et al. ${ }^{7}$ affirmed that even when faced with a slow growing AOF, intra and extraoral exam must be performed, because this lesion may cause an intrabucal increase in volume, with a hardened consistency, however, the color of the mucosa remains pink, and in general, there is slight facial asymmetry ${ }^{11}$. Nelson \& Thompson ${ }^{5}$, Franco et al. ${ }^{2}$ and De Riu et al. ${ }^{11}$ alleged that the patient feels no pain and reports no previous history of infections or local traumas. The patient in the case reported presented no intraoral increase in volume or change in color of the gingiva, had no local discomfort and systemic changes in health.

According to De Riu et al. ${ }^{11}$ and Tolentino et al. ${ }^{12}$, the tumor may inhibit eruption of the tooth involved. In the present case, agenesis of tooth 38 was diagnosed, and the tumor had not affected tooth 37, which was found in the routine panoramic radiograph taken for the purpose of having third molars extracted ${ }^{3-4}$.

In the panoramic radiograph, according to Mummolo et al. ${ }^{3}$ and Boxberger et al. ${ }^{4}$, and from the aspects visualized in the case presented, the ameloblastic fibroodontoma appeared as a well circumscribed radiolucent lesion, with an radiopaque mass inside it.

The histopathological exam of the biopsy performed on the patient showed an epithelium that was sometimes in cords and sometimes in islands, with the presence of juxtaposed ameloblasts that resembled the tooth germ. After surgical removal of the tumor, a new histopathological exam confirmed the diagnosis of AFO, showing the odontogenic epithelium in ample cellular proliferation, with numerous islands and cell cords on the loose conjunctive tissue that resembled dental pulp.

Santos et al. ${ }^{16}$ affirmed that it was possible to diagnose an AFO only by correlating the clinical data with imaging exams and performing a biopsy, and the case presented is in agreement with this author, because it was diagnosed by means of these three exams. In turn, Mummolo et al. ${ }^{3}$ based their diagnosis on the presence or absence of elements indicative of differentiation of the dental germ in the histopathological exam, which was confirmed by the biopsy performed in the case here reported, in which mineralized tissue similar to dental cement was observed.

As the lesion presented in this study was relatively small $(25 \mathrm{~mm})$; did not attain cortical bone, and was presented in an encapsulated form, conservative surgery with meticulous curettage was performed, as recommended by various authors, for example, Boxberger et al. ${ }^{4}$, Lúcio et al. ${ }^{10}$ and Buchner et al. ${ }^{7}$. Curettage is 
indicated, considering that normally recurrences arise from a residual lesion resulting from initially inadequate surgery ${ }^{7}$. Santos et al. ${ }^{16}$ recommended long-term follow-up, although the AFO presents a low rate of recurrence. The patient in the present article has been followed up on a sixmonthly basis by means of clinical radiographic exam for 2 years, without signs of recurrence

\section{CONCLUSION}

In the case presented, with exception of the patient's gender, the remaining clinical-radiographic and histopathological characteristics were similar to those

\section{REFERENCES}

1. Hegde V, Hemavathy S. A massive ameloblastic fibro-odontoma of the maxilla. Indian J Dent Res. 2008;19(2):162-4.

2. Franco A, Riscala S, Kahoudji M, Croue A. Endoscopic removal of a mandibular ameloblastic fibro-odontoma. Rev Stomatol Chir Maxillofac. 2009;110(6):359-61. doi: 10.1016/j. stomax.2009.03.011

3. Mummolo S, Marchetti E, Di Martino S, Scorzetti L, Marzo G. Ameloblastic fibro-odontoma: a case report. Ann Stomatol (Roma). 2010;1(2):11-3.

4. Boxberger NR, Brannon RB, Fowler CB. Ameloblastic fibroodontoma: a clinicopathologic study of 12 cases. J Clin Pediatr Dent. 2011;35(4):397-403.

5. Nelson BL, Thompson LD. Ameloblastic fibro-odontoma. Head Neck Pathol. 2014;8(2):168-70. doi: 10.1007/s12105-0130501-9

6. Howell RM, Burkes EJ Jr. Malignant transformation of ameloblastic fibro-odontoma to ameloblastic fibrosarcoma. Oral Surg Oral Med Oral Pathol. 1977;43(3):391-401.

7. Buchner A, Kaffe I, Vered M. Clinical and radiological profile of ameloblastic fibro-odontoma: an update on an uncommon odontogenic tumor based on a critical analysis of 114 cases. Head Neck Pathol. 2013;7(1):54-63. doi: 10.1007/s12105-0120397-9

8. Zouhary KJ, Said-Al-Naief N, Waite PD. Ameloblastic fibroodontoma: expansile mixed radiolucent lesion in the posterior maxilla: a case report. Oral Surg Oral Med Oral Pathol Oral Radiol Endod. 2008;106(4):e15-21. doi: 10.1016/j.tripleo.2008.05.038

9. Hunter AK, Muller S, Kalathingal SM, Burnham MA, Moore WS. Evaluation of an ameloblastic fibro-odontoma with cone beam computed tomography. Tex Dent J. 2012;129(6):619-24. described in the literature. The treatment proposed was shown to be effective and the post-surgical follow-up of two years presented no evidence of recurrence of the lesion.

\section{Collaborators}

CG PIVA e I RINALDI were responsible for the academic follow-up and review of the literature. DC MIYAGAKI participated in writing the article. MS LINDEN and $F$ DE CONTO were responsible for performing the surgery in the case. JP DE CARLI was responible for the histopathological analysis.

10. Lucio PS, Cavalcante RB, Maia RN, Santos ES, Godoy GP Aggressive ameloblastic fibro-odontoma assessment with $C B C T$ and treatment. Eur Arch Paediatr Dent. 2013;14(3):179-84. doi: 10.1007/s40368-013-0032-9

11. De Riu G, Meloni SM, Contini M, Tullio A. Ameloblastic fibro-odontoma. Case report and review of the literature. J Craniomaxillofac Surg. 2010 Mar;38(2):141-4. doi: 10.1016/j. jcms.2009.04.009

12. de Souza Tolentino E, Centurion BS, Lima MC, Freitas-Faria P, Consolaro A, Sant'ana E. Ameloblastic fibro-odontoma: a diagnostic challenge. Int J Dent. 2010;2010: 104630. doi: $10.1155 / 2010 / 104630$

13. Cavalcante AS, Anbinder AL, Costa NC, Lima JR, Carvalho YR Ameloblastic fibro-odontoma: a case report. Med Oral Patol Oral Cir Bucal. 2009;14(12):e650-3.

14. Nascimento JE, Araujo LD, Almeida LY, De Paula AM, Bonan PR Ameloblastic fibro-odontoma: a conservative surgical approach. Med Oral Patol Oral Cir Bucal. 2009;14(12):e654-7. doi 10.4317/medoral.14.e654

15. Wewel J, Narayana N. Ameloblastic fibro-odontoma of the anterior mandible in a 22-month-old boy. Indian J Dent Res 2010;21(4):618-20. doi: 10.4103/0970-9290.74237

16. Santos TS, de Carvalho RW, Avelar RL, Dias de Oliveira e Silva E, Frota R, Anjos ED. Ameloblastic fibro-odontoma in children: report of 2 cases. J Dent Child (Chic). 2011 Sep-Dec;78(3):173-7. 